\title{
FGF14 modulates resurgent sodium current in mouse cerebellar Purkinje neurons
}

\author{
Haidun Yan ${ }^{1,2}$, Juan L Pablo ${ }^{2,3}$, Chaojian Wang ${ }^{1,2}$, Geoffrey S Pittt,2,3* \\ 'Department of Medicine, Duke University Medical Center, Durham, United States; \\ ${ }^{2}$ Ion Channel Research Unit, Duke University Medical Center, Durham, United States; \\ ${ }^{3}$ Department of Neurobiology, Duke University Medical Center, Durham, United States
}

*For correspondence: geoffrey. pitt@duke.edu

Competing interests: The authors declare that no competing interests exist.

Funding: See page 13

Received: 30 July 2014

Accepted: 29 September 2014

Published: 30 September 2014

Reviewing editor: Gary L Westbrook, Vollum Institute, United States

Copyright Yan et al. This article is distributed under the terms of the Creative Commons Attribution License, which permits unrestricted use and redistribution provided that the original author and source are credited.
Abstract Rapid firing of cerebellar Purkinje neurons is facilitated in part by a voltage-gated $\mathrm{Na}^{+}\left(\mathrm{Na}_{v}\right)$ 'resurgent' current, which allows renewed $\mathrm{Na}^{+}$influx during membrane repolarization. Resurgent current results from unbinding of a blocking particle that competes with normal channel inactivation. The underlying molecular components contributing to resurgent current have not been fully identified. In this study, we show that the Nav channel auxiliary subunit FGF14 'b' isoform, a locus for inherited spinocerebellar ataxias, controls resurgent current and repetitive firing in Purkinje neurons. FGF14 knockdown biased $\mathrm{Na}_{v}$ channels towards the inactivated state by decreasing channel availability, diminishing the 'late' $\mathrm{Na}_{\mathrm{v}}$ current, and accelerating channel inactivation rate, thereby reducing resurgent current and repetitive spiking. Critical for these effects was both the alternatively spliced FGF14b N-terminus and direct interaction between FGF14b and the $\mathrm{Na}_{\mathrm{V}} \mathrm{C}$-terminus. Together, these data suggest that the FGF14b N-terminus is a potent regulator of resurgent $\mathrm{Na}_{V}$ current in cerebellar Purkinje neurons.

DOI: 10.7554/eLife.04193.001

\section{Introduction}

Cerebellar Purkinje neurons, which provide the sole output from the cerebellar cortex, display a repetitive firing behavior driven by voltage-gated $\mathrm{Na}^{+}$channels ( $\mathrm{Na}_{v}$ channels). Fast repetitive firing in Purkinje neurons is promoted by unusual characteristics associated with $\mathrm{Na}$ v channel inactivation, whereby channels recover unusually rapidly from inactivation and in doing so pass a 'resurgent' sodium current, which helps drive the cell to fire a subsequent action potential. The molecular components underlying the peculiar properties of $\mathrm{Na}_{v}$ channels in Purkinje neurons have not been definitively identified.

Several features of $\mathrm{Na}_{v}$ currents in cerebellar Purkinje neurons, however, set them apart from $\mathrm{Na}_{v}$ currents recorded in other neurons. First, more than half of the $\mathrm{Na}_{\mathrm{v}}$ current in Purkinje neurons is carried by $\mathrm{Na}_{v} 1.6$, an isoform for which inactivation is less complete compared to other $\mathrm{Na}_{v}$ channels (Raman et al., 1997). Examination of $\mathrm{Na}_{\mathrm{v}}$ currents in cerebellar Purkinje neurons from Scn8a ${ }^{-/-}$mice showed that, compared to the other resident $\mathrm{Na}_{v}$ channels, the Scn8a-encoded $\mathrm{Na}_{v} 1.6$ channels have a relatively large 'late' (non-inactivating) component and Nav1.6 channels have increased availability (depolarized $\mathrm{V}_{1 / 2}$ for steady-state inactivation). Second, $\mathrm{Na}_{V}$ channels in cerebellar Purkinje neurons display an unusual transient re-opening during repolarization, which is identified as 'resurgent' $\mathrm{Na}_{v}$ current (Raman and Bean, 1997). This resurgent current derives from an unblocking of open channels by a peptide moiety that can be eliminated by the intracellular application of trypsin or chymotrypsin proteases into the cytoplasm (Grieco et al., 2005). The blocking particle acts only on open channels and competes with the inactivation process to prevent channels from entering an absorbed, inactivated state. During action potential repolarization, unblocking of these channels then allows $\mathrm{Na}^{+}$influx that can initiate a subsequent action potential (Khaliq et al., 2003). Since the $\mathrm{Na}_{v}$ current in Purkinje 
eLife digest The cerebellum is a region of the brain that is involved in motor control, and it contains a special type of nerve cells called Purkinje neurons. Messages travel along neurons as electrical signals carried by sodium ions, which have a positive electric charge. Normally, when a neuron is 'at rest', the plasma membrane that surrounds the neuron prevents the sodium ions outside the cell from entering. To send an electrical signal, voltage-sensitive proteins in the membrane called sodium channels open up. This allows the sodium ions to enter the cell by passing through a pore in the channel protein, thereby changing the voltage across the membrane.

Once sodium channels open, they rapidly become 'locked' in a closed state, which allows the membrane voltage to return to its original value before another signal can be sent. This locked state also prevents sodium channels from reopening quickly. As a consequence most neurons cannot send successive electrical signals rapidly. Purkinje neurons are unusual because they can send many electrical signals in quick succession — known as rapid firing — without having to be reset each time.

Rapid firing is possible in Purkinje neurons because the channel proteins can be reopened to allow more $\mathrm{Na}^{+}$to enter the cell, but it is not clear how this is controlled. Now, based on experiments on Purkinje neurons isolated from mice, Yan et al. have shown that a protein called FGF14 that binds to the sodium channel proteins can help them to reopen quickly in order to allow rapid firing.

Spinocerebellar ataxia is a degenerative disease caused by damage to the cerebellum that leads to loss of physical coordination. Some patients suffering from this disease carry mutations in the gene that makes the FGF14 protein. Therefore, understanding the role of FGF14 in the rapid firing of Purkinje neurons may aid the development of new treatments for this disease.

DOI: 10.7554/eLife.04193.002

neurons carried by $\mathrm{Na}_{v} 1.6$ is relatively resistant to inactivation, it is particularly susceptible to open block by the peptide moiety. Why Nav1.6 channels in cerebellar Purkinje neurons are relatively resistant to inactivation, however, is unknown.

Here, we focused on the role of the ion channel regulator FGF14, which is enriched in cerebellar granule and Purkinje neurons (Wang et al., 2002). FGF14 is one of four fibroblast growth factor homologous factors (FHFs), members of the fibroblast growth factor (FGF) superfamily sharing a FGFlike core but having extended N- and C-termini not found in other FGFs. Individual FHFs undergo alternative splicing that generates distinct $\mathrm{N}$-termini, none of which contain a signal sequence (Smallwood et al., 1996; Munoz-Sanjuan et al., 2000). Thus, unlike other FGFs they are not secreted and do not function as growth factors (Smallwood et al., 1996). Instead, FHFs remain intracellular and modulate various ion channels. FHFs can bind directly to the cytoplasmic C-terminal domains (CTDs) of $\mathrm{Na}_{v}$ channels (Liu et al., 2001) and regulate $\mathrm{Na}_{v}$ channel function (Lou et al., 2005). Further, FGF14 is a potent regulator of both $\mathrm{Na}_{\mathrm{v}} 1.1$ and $\mathrm{Na}_{\mathrm{v}} 1.6$ (Lou et al., 2005; Laezza et al., 2009), the two dominant $\mathrm{Nav}_{\mathrm{v}}$ channels in cerebellar Purkinje neurons (Raman et al., 1997; Kalume et al., 2007). FHFs also regulate voltage-gated $\mathrm{Ca}^{2+}$ channels through a mechanism that does not appear to involve a direct interaction (Hennessey et al., 2013; Yan et al., 2013). An ataxia phenotype in $\mathrm{Fgf14}^{-/-}$mice highlights the role of FGF14 in cerebellar physiology and the development of spinocerebellar ataxia type 27 (SCA27) in patients with either FGF14 haploinsufficiency or a dominant negative FGF14 mutation (Wang et al., 2002; van Swieten et al., 2003; Dalski et al., 2005) underscores the role of FGF14 in disease.

Using shRNA knockdown of endogenous FGF14 in cultured cerebellar Purkinje neurons and replacement with informative mutants that blocked binding of FGF14 to $\mathrm{Na}_{\mathrm{V}}$ CTDs and eliminated the FGF14 extended N-terminus, we found that FGF14, and especially the N-terminus of the FGF14b isoform exerts specific kinetic effects on cerebellar $\mathrm{Na}_{v}$ channels that support repetitive firing and therefore provides new information on the pathophysiology of SCA27.

\section{Results}

To test whether FGF14 was a contributor to regulation of $\mathrm{Na}_{v}$ current in cerebellar Purkinje neurons, we first confirmed its expression in cerebellum and demonstrated that FGF14 co-immunoprecipitates with $\mathrm{Na}_{\mathrm{v}} 1.6$ channels in mouse cerebellar lysates (Figure 1A). Although FGF14 was previously shown 


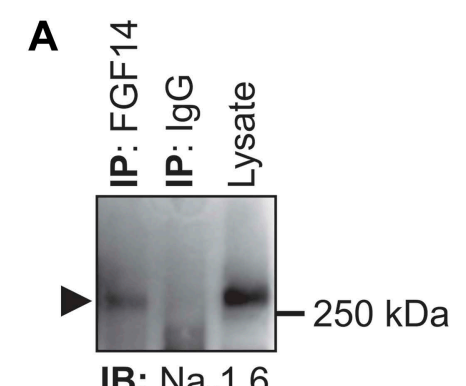

IB: $\mathrm{Na}_{\mathrm{v}} 1.6$

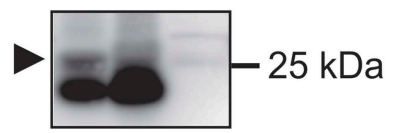

IB: FGF14
B

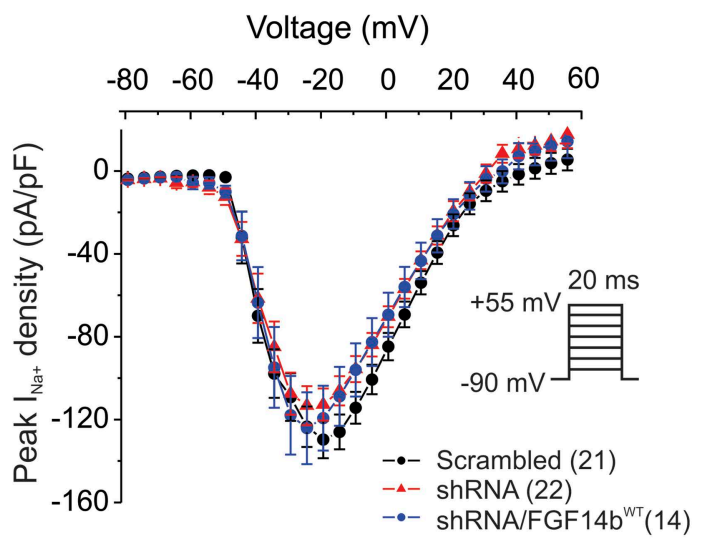

Figure 1. FGF14 is a component of the Nav1.6 macromolecular complex in mouse cerebellum, but shRNA knockdown does not affect $\mathrm{Na}_{v}$ current density in cultured cerebellar Purkinje neurons. (A) Co-immunoprecipitation (IP) of $\mathrm{Na}_{v} 1.6$ by FGF14 from mouse cerebellum and immunoblot (IB) with the indicated antibodies. $\mathrm{M}_{w}$ markers are indicated on right. Arrowheads indicate Nav1.6 (top panel) and FGF14 (bottom panel). Intense signal in bottom panel below the FGF14 signal is immunoglobulin light chain. (B) Current-voltage relationships (normalized to cell capacitance) of transient $\mathrm{Na}_{v}$ currents from cerebellar Purkinje neurons transfected with Scrambled control shRNA (Scrambled), FGF14 shRNA (shRNA), or FGF14 shRNA plus the shRNA-resistant FGF14bwT (shRNA/FGF14wT). The number of neurons tested, $N$, is in parentheses. Inset shows schematic of voltage protocol.

DOI: 10.7554/eLife.04193.003

to co-immunoprecipitate with $\mathrm{Na}_{v} 1.6$ in a heterologous expression system (Laezza et al., 2009), co-immunoprecipitation between FGF14 and $\mathrm{Na}_{\mathrm{v}} 1.6$ channels has not been reported from brain.

To evaluate the consequences of FGF14 haploinsufficiency in SCA27, we used a previously validated shRNA (Yan et al., 2013) to knockdown endogenous FGF14 in cultured cerebellar Purkinje neurons. Knockdown of FGF14 did not affect $\mathrm{Na}_{v}$ current density compared to the $\mathrm{Na}_{v}$ current density recorded in neurons transfected with a control shRNA (Figure 1B). Because knockout of Fgf14 reduced spiking activity (Goldfarb et al., 2007) but $\mathrm{Na}_{\mathrm{v}}$ current density was unaffected in Fgf14 knockout or knockdown, we hypothesized that the absence of FGF14 must affect $\mathrm{Na}_{v}$ kinetic properties in ways that prevent repetitive firing. We therefore examined $\mathrm{Na}_{v}$ kinetic properties in more detail.

Voltage dependence of activation was unaffected by FGF14 knockdown (Figure 2A), but the $\mathrm{V}_{1 / 2}$ of steady-state inactivation was shifted about $-10 \mathrm{mV}$, thereby decreasing channel availability (Figure 2B and Table 1). When we co-expressed a FGF14b cDNA with synonymous substitutions rendering it resistant to the FGF14 shRNA (FGF14b'TT), the $V_{1 / 2}$ of steady-state inactivation was restored to the control voltage; activation was unaffected (Figure 2A-B and Table 1). The 'rescue' of steady-state inactivation by expression of the shRNA-insensitive FGF14 provided additional demonstration of the specificity of our shRNA targeting strategy (and see similar rescue for additional parameters below). In addition to the decreased channel availability, we observed that FGF14 knockdown accelerated inactivation kinetics (Figure 2C-D). FGF14 knockdown also reduced the late $\mathrm{Na}_{v}$ current (Figure 2E-F). Thus, by several different kinetic measures, FGF14 knockdown in cerebellar Purkinje neurons biased the endogenous $\mathrm{Na}_{v}$ channels towards entering the inactivated state. We anticipated, therefore, that FGF14 knockdown should reduce $\mathrm{Na}_{v}$ resurgent current amplitude, a key feature that allows cerebellar Purkinje neurons to fire repetitively. Indeed, the amplitude of the resurgent $\mathrm{Na}_{v}$ current (Figure $2 \mathrm{G}-J$ ) was markedly diminished using a well-established protocol to elicit Nav resurgent current (Raman and Bean, 1997). As with the other kinetic properties of $\mathrm{Na}_{v}$ currents (above), co-expression of FGF14b ${ }^{\mathrm{WT}}$ in the presence of the shRNA provided a complete rescue (Figure 2G-J). While FGF14 knockdown reduced the amplitude of resurgent $\mathrm{Na}_{\vee}$ current, it did not significantly affect the time to peak (Figure $2 K$ ).

To determine how FGF14 regulates $\mathrm{Na}_{v}$ kinetics and $\mathrm{Na}_{v}$ resurgent current, we turned our focus to the FGF14 N-terminus. The alternatively spliced $\mathrm{N}$-termini of various FHFs have been shown to exert 
A

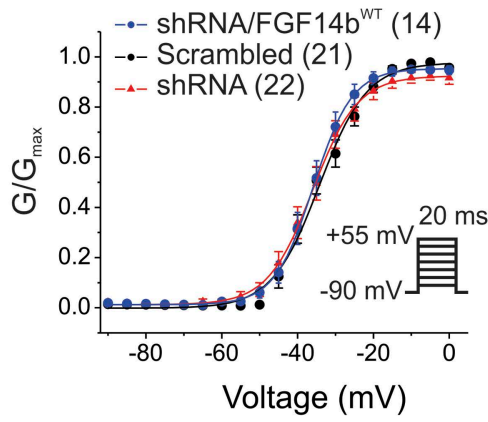

B

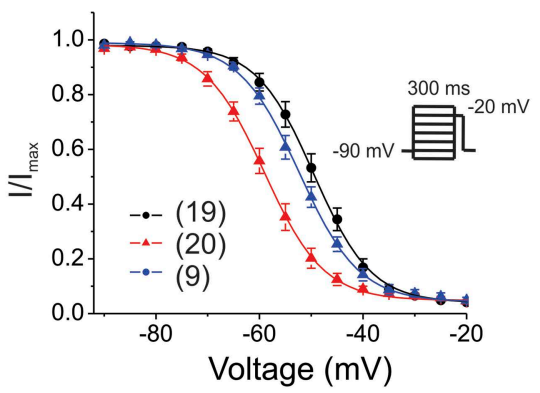

E

F
D

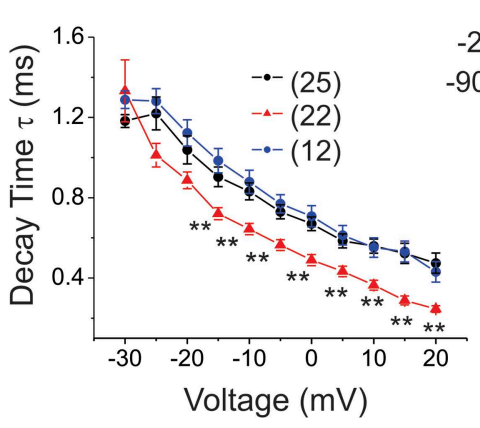

H

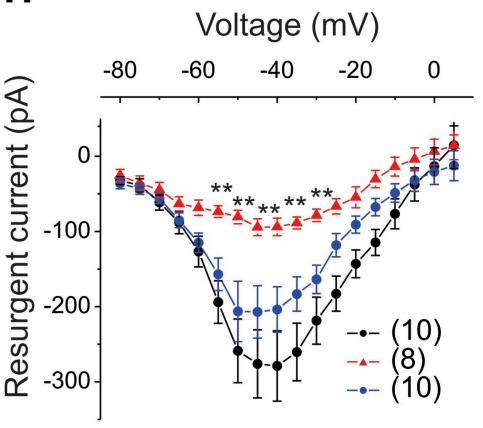

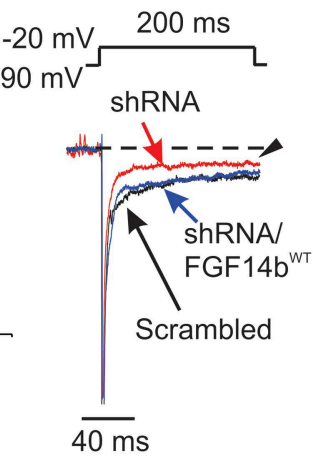

C

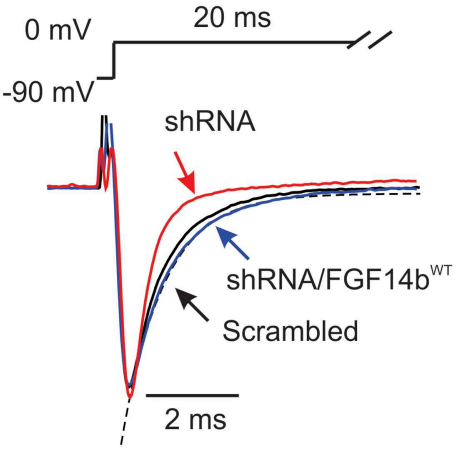

G

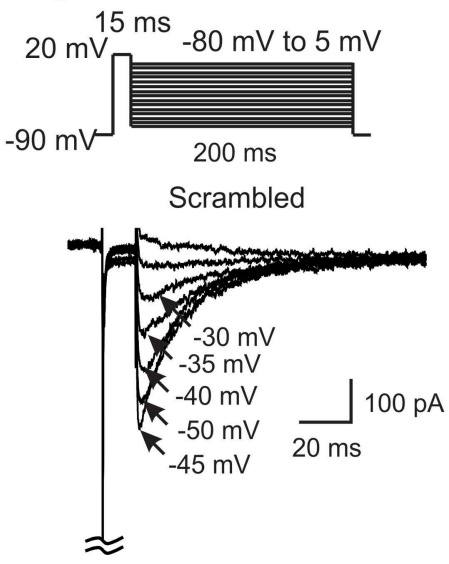

I

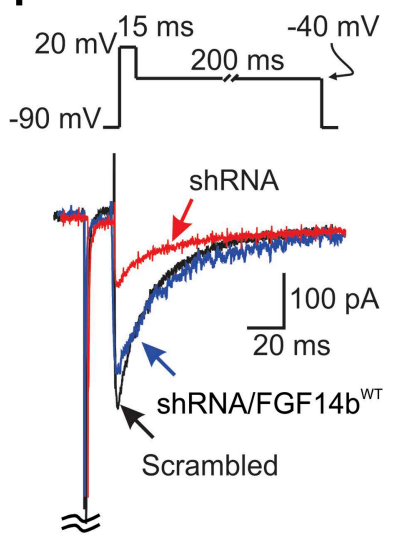

J

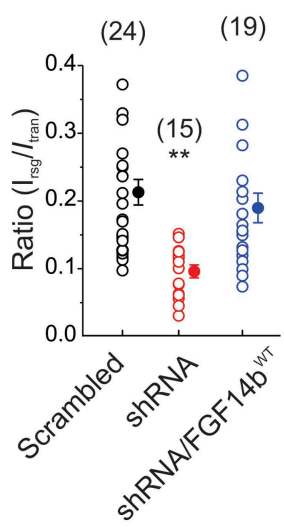

K

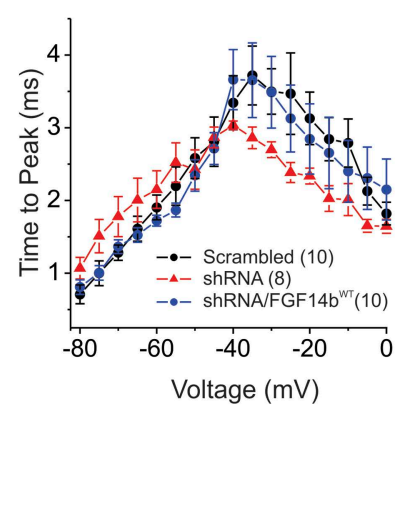

Figure 2. FGF14 knockdown in cerebellar Purkinje neurons affects multiple $\mathrm{Na}_{v}$ channel biophysical properties. (A and B) Voltage-dependence of Nav channel activation and steady-state inactivation in cerebellar Purkinje neurons transfected with Scrambled control shRNA (Scrambled), FGF14 shRNA (shRNA), or FGF14 shRNA plus the shRNA-resistant FGF14b'wT (shRNA/FGF14wT). The number of neurons tested, $N$, is in parentheses. Inset shows schematic of voltage protocol. (C) Exemplar normalized $\mathrm{Na}_{v}$ current traces elicited with a step depolarization to $0 \mathrm{mV}$ from a holding potential of $-90 \mathrm{mV}$ and an exemplar single exponential fit (for Scrambled) for the time constant (T) of inactivation (dotted line). (D) T of inactivation at the indicated test voltages. The number of neurons tested, $N$, is in parentheses. ${ }^{\star *} p<0.01$. (E) Exemplar normalized TTX-sensitive late $\mathrm{Nav}$ currents at $-20 \mathrm{mV}$ (measured at $150 \mathrm{~ms}$, arrowhead) from a holding potential of $-90 \mathrm{mV}$. (F) Amplitude of late $\mathrm{Na}_{\mathrm{v}}$ current as a \% of peak (transient) $\mathrm{Na} \mathrm{v}_{\mathrm{V}}$ current. The number of neurons tested, $N$, is in parentheses. ${ }^{\star \star} p<0.01$. (G) Voltage-clamp protocol and exemplar TTX-sensitive resurgent Nav currents recorded from cerebellar Purkinje neurons transfected with Scrambled control shRNA. The transient current has been clipped. (H) Current-voltage relationship of Nav resurgent currents. The number of neurons tested, $N$, is in parentheses. ${ }^{* \star} \mathrm{p}<0.01$. (I) Overlay of $\mathrm{Na}_{v}$ resurgent currents for the indicated conditions recorded with Figure 2. Continued on next page 
Figure 2. Continued

the indicated voltage protocol. The transient current has been clipped. (J) Ratio of peak Nav resurgent current (at $+20 \mathrm{mV}$ ) to transient $\mathrm{Na} \mathrm{v}_{\mathrm{v}}$ current (at $-10 \mathrm{mV}$ ). The number of neurons tested, $N$, is in parentheses. ${ }^{\star *} \mathrm{p}<0.01$. (K) Time to peak of $\mathrm{Nav}$ resurgent current over a broad range of voltages. The number of neurons tested, $N$, is in parentheses. ${ }^{* *} p<0.01$.

specific effects on $\mathrm{Na}_{\mathrm{V}}$ currents (Lou et al., 2005; Rush et al., 2006), including the regulation of inactivation kinetics (Laezza et al., 2009; Dover et al., 2010), but the role of the FGF14 N-termini have not been investigated in cerebellar Purkinje neurons. FGF14b is the predominant FGF14 splice variant expressed in brain (Wang et al., 2000, 2011) and the FGF14 splice variant found in the cytoplasm; FGF14a is localized to the nucleus (Wang et al., 2000). To test the specific roles of the FGF14b $\mathrm{N}$-terminus, we expressed a FGF14 in which the N-terminus was deleted (FGF14 ${ }^{N T}$ ). Because the interaction site for the $\mathrm{Na}_{V}$ CTD on FHFs lies within the conserved core domain (Wang et al., 2012), deletion of the $\mathrm{N}$-terminus does not affect interaction with the $\mathrm{Nav}$ CTD. Thus, the FGF14 $\Delta^{\mathrm{NT}}$ exerts a dominant negative effect by competing with endogenous FGF14 for interaction with the $\mathrm{Na}_{V}$ CTD (Figure 3A). Current density (Figure $3 B$ ) and the $V_{1 / 2}$ of activation (Figure $3 C$ and Table 1) were unaffected. However, expression of FGF14 $\Delta^{N T}$ shifted the $V_{1 / 2}$ of steady-state inactivation about $-10 \mathrm{mV}$ (Figure 3C), accelerated kinetics of inactivation (Figure 3D), reduced the late $\mathrm{Na}_{V}$ current (Figure 3E), and diminished resurgent current (Figure 3F) to a degree similar to or even greater than shRNA knockdown. FGF14 $\Delta^{\mathrm{NT}}$ diminished resurgent $\mathrm{Na}_{v}$ current even more effectively than shRNA knockdown of FGF14. As a control, we overexpressed the FGF14bWT that had rescued the parameters affected by shRNA knockdown (Figure 1). Overexpression of FGF14bWT here was without effect (Figure 3 and Table 1). Not only did this serve as a control for FGF14 $\Delta^{N T}$, but these data suggest that endogenous FGF14b is saturating. These data also suggest that FGF14b's main regulatory component for Purkinje neuron $\mathrm{Na}_{\vee}$ currents lies within the FGF14b N-terminus.

The dominant negative effect exerted by FGF14 $\Delta^{\mathrm{NT}}$ as it replaced the endogenous FGF14 on the $\mathrm{Na}_{V}$ CTD implied that although FGF14 regulates $\mathrm{Na}_{\mathrm{V}}$ current through its $\mathrm{N}$-terminus, it may require that FGF14 be in direct interaction with the channel. To test this hypothesis specifically, we designed a FGF14b that was unable to bind to the channel CTD and examined whether expression of this mutant could restore the diminished resurgent current resulting from shRNA knockdown of FGF14. Structural determination of a ternary complex containing FGF13, the Nav1.5 CTD, and calmodulin had identified key amino acids on the conserved FHF interaction surface that participated in the interaction with the conserved $\mathrm{Na}_{V}$ CTD surface (Wang et al., 2012). We focused on a highly conserved Arg in the FHF core domain (Arg57 in FGF13U, equivalent to Arg117 in FGF14b), which inserts into a deep pocket on the $\mathrm{Na}_{\mathrm{v}} 1.5$ CTD binding surface (Figure 4A). We therefore generated the homologous R117A mutant (FGF14b/A) in the FGF14b shRNA-resistant cDNA background and tested whether FGF14b/A could bind to the intact $\mathrm{Na} \mathrm{b}_{\mathrm{V}} 1.6$. Although immunoprecipitation of FGF14bWT from lysates of HEK293 cells transfected with FGF14bWT and Nav1.6 showed coimmunoprecipitation of $\mathrm{Na}_{\vee} 1.6$, the mutant FGF14bR/A was unable to co-immunoprecipitate $\mathrm{Na}_{\mathrm{v}} 1.6$ (Figure 4B). Thus, mutation of R117A in FGF14b prevents interaction with $\mathrm{Na}_{\mathrm{v}} 1.6$. We therefore transfected the shRNA-resistant FGF14b ${ }^{R / A}$ (or the shRNA-resistant FGF14bWT) along with the FGF14 shRNA into cultured cerebellar Purkinje neurons to determine the effect of FGF14 interaction with $\mathrm{Na}_{v} 1.6$ on $\mathrm{Na}_{v}$ currents. Expression of FGF14bR/A after shRNA knockdown of endogenous FGF14 had no effect on $\mathrm{Na}_{v}$ current density (Figure 4C). In contrast to the rescue afforded by FGF14bWT, FGF14bR/A did not rescue the key parameters that lead to increased inactivation observed after FGF14 shRNA. Nav late current and the time constant of inactivation were not different from shRNA (Figure 4D-F). Consistent with these findings, we observed the expected reduction in resurgent $\mathrm{Na}_{v}$ current (Figure $4 \mathrm{G}-H$ ). Thus, the FGF14 N-terminus must exert its key effects through FGF14's direct interaction with the $\mathrm{Na}_{\mathrm{V}} \mathrm{C}$-terminus.

Because the absence of the FGF14 or its N-terminus accelerated $\mathrm{Na}_{v}$ channel inactivation, diminished late current, and decreased resurgent current, we anticipated that the resultant bias towards $\mathrm{Na}_{\mathrm{V}}$ inactivation would adversely affect excitability in cerebellar Purkinje neurons. We tested this hypothesis by determining the effects of the FGF14 and its N-terminus on action potential threshold and on the number of action potentials evoked with depolarizing current injections in current-clamp mode. Under our culture conditions ( $\leq 14$ days in vitro), we found that $8-10 \%$ of cerebellar Purkinje 
Table 1. $\mathrm{Na}_{\mathrm{v}}$ current activation and inactivation parameters in cerebellar Purkinje neurons

\begin{tabular}{|c|c|c|c|c|c|c|}
\hline & Activation & & & Inactivation & & \\
\hline & $\mathrm{V}_{1 / 2}(\mathrm{mV})$ & $K$ & $\mathbf{n}$ & $\mathrm{V}_{1 / 2}(\mathrm{mV})$ & $K$ & $\mathbf{n}$ \\
\hline Scrambled & $-34.4 \pm 1.5$ & $4.0 \pm 0.3$ & 21 & $-49.7 \pm 1.2$ & $4.2 \pm 0.1$ & 19 \\
\hline shRNA & $-35.0 \pm 1.9$ & $4.3 \pm 0.5$ & 22 & $-59.0 \pm 1.2^{\star \star}$ & $4.7 \pm 0.2$ & 20 \\
\hline shRNA/FGF14bwt & $-35.5 \pm 1.5$ & $3.9 \pm 0.3$ & 14 & $-52.0 \pm 0.9$ & $5.2 \pm 0.3$ & 9 \\
\hline shRNA/FGF14 ${ }^{\text {RA }}$ & $-33.2 \pm 1.5$ & $3.5 \pm 0.2$ & 12 & $-50.9 \pm 1.4$ & $4.4 \pm 0.3$ & 11 \\
\hline FGF14bWT & $-33.1 \pm 1.4$ & $4.5 \pm 0.5$ & 14 & $-50.6 \pm 1.3$ & $4.9 \pm 0.3$ & 10 \\
\hline $\mathrm{FGF14} \Delta^{\mathrm{NT}}$ & $-33.9 \pm 2.0$ & $3.9 \pm 0.5$ & 14 & $-59.1 \pm 0.8^{\star \star}$ & $4.7 \pm 0.3$ & 15 \\
\hline
\end{tabular}

Mean \pm s.e.m. (n), ${ }^{\star *} p<0.01$ compared to Scrambled control.

DOI: 10.7554/eLife.04193.005

neurons exhibit spontaneous action potentials (firing rate 5-20 Hz) with regular and irregular patterns. When neurons were cultured for extended periods ( $>20$ days in vitro), we observed that $\sim 50 \%$ of Purkinje neurons spontaneously fired-more similar to acutely isolated Purkinje neurons (Raman and Bean, 1999) and cultured Purkinje neurons (Gruol and Franklin, 1987). These data suggest that spontaneous activity depends upon the maturity of the neurons in culture. Because of the difficulty in achieving voltage clamp on Purkinje neurons $\geq 14$ days in vitro, our voltage-clamp experiments were performed on the younger cells (Figures 2-4). Thus, we continued with immature neurons for these experiments, and focused on measuring evoked action potentials rather than spontaneous action potentials. Single action potentials were evoked by a 10 -ms current injection with 5-pA increments to determine the current threshold to initiate an action potential. Figure 5A-B and Table 2 show that FGF14 knockdown and expression of the dominant negative FGF14b $\Delta^{\mathrm{NT}}$ markedly increased the current threshold to produce an action potential; other action potential parameters were not affected. Rescue of FGF14 knockdown by co-expression of FGF14b'WT restored the current threshold to control levels. Rescue with the non-interacting FGF14b/A did not. We also analyzed the number of actions evoked during $600 \mathrm{~ms}$ current injection over a wide range of current amplitudes. The number of action potentials evoked was significantly larger in control (scrambled shRNA) neurons than in neurons transfected with FGF14 shRNA. Rescue with FGF14b't, but not FGF14b $\mathrm{R} / \mathrm{A}$, restored the number of evoked action potentials to control levels. Expression of the dominant negative FGF14b $\Delta^{\mathrm{NT}}$ reduced the number of evoked action potentials to the level observed after FGF14 knockdown (Figure 5C-D). Thus, as observed for the individual $\mathrm{Na}_{v}$ channel kinetic parameters, FGF14b, and its N-terminus specifically, is a critical regulator of neuronal firing and intrinsic membrane properties.

\section{Discussion}

Although FGF14 haploinsufficiency is associated with spinocerebellar ataxia (Dalski et al., 2005) and intrinsic excitability of cerebellar Purkinje neurons is reduced in $\mathrm{Fgf14}^{-/-}$mice (Shakkottai et al., 2009), the detailed multifactorial molecular mechanisms by which FGF14 affects neuronal excitability were not previously known. We had found that FGF14 knockdown in cerebellar granule neurons reduced presynaptic voltage-gated $\mathrm{Ca}^{2+}$ currents and thereby affected neurotransmission at the cerebellar granule neuron to Purkinje neuron synapse (Yan et al., 2013). Here, we found that FGF14b in cerebellar Purkinje neurons affects multiple kinetic parameters of $\mathrm{Na}_{v}$ channels, thereby reducing the resurgent $\mathrm{Na}_{v}$ current that underlies repetitive firing. Together, the accelerated inactivation, reduced channel availability, and decreased late current observed after FGF14 knockdown bias Nav channels to the inactivated state. Thus, the blocking particle that competes with the inactivation gate for open $\mathrm{Na}_{V}$ channels is disadvantaged. Consequently, the resurgent current, and the resulting ability to support repetitive firing in Purkinje neurons, is reduced as we observed. Thus, our data show that an essential regulatory feature of FGF14 in cerebellar Purkinje neurons is to slow $\mathrm{Na}_{v}$ channel inactivation in order to foster resurgent current.

Resurgent current results from the actions on $\mathrm{Na}_{v} 1.6$ of a putative blocking particle, which is thought to be the cytoplasmic C-terminal peptide of the $\mathrm{Na}_{v}$ auxiliary $\mathrm{Na}_{v} \beta 4$ subunit (Grieco et al., 2005). 
A

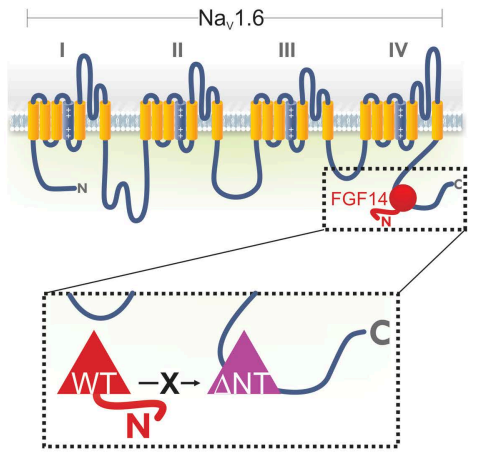

C

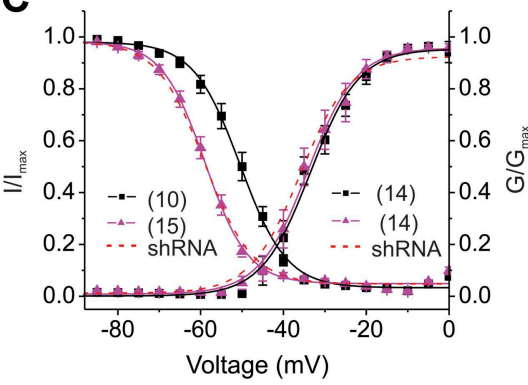

E

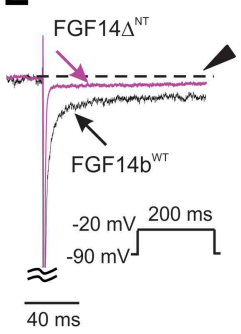

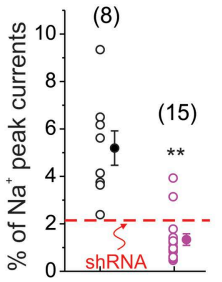

FGF14b ${ }^{\text {WT }} \mathrm{FGF} 14 \Delta^{\mathrm{NT}}$

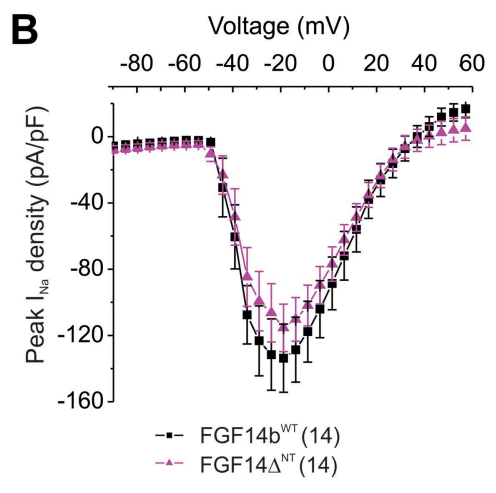

D

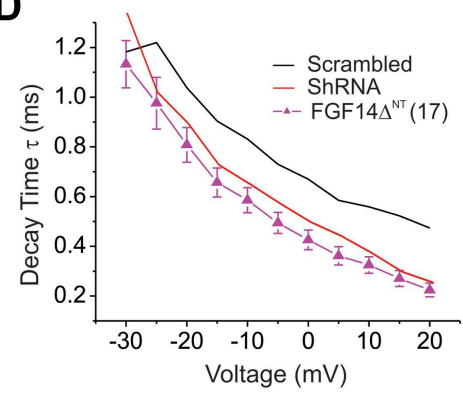

$\mathbf{F}$

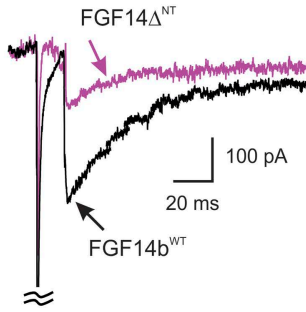

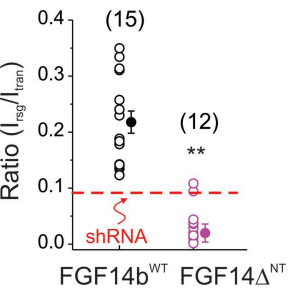

Figure 3. Expression of the dominant negative FGF14 $\Delta^{N T}$ affects multiple $\mathrm{Na}_{v}$ channel biophysical properties indicating essential roles for the FGF14 N-terminus. (A) Schematic of endogenous wild type (WT) FGF14 binding to the C-terminus of the Nav1.6 $\alpha$ subunit (top) and magnified schematic of the expressed FGF14 $\Delta^{\mathrm{NT}}$ preventing binding of the WT FGF14 (in box). (B) Current-voltage relationships (normalized to cell capacitance) of transient $\mathrm{Na} a_{v}$ currents from cerebellar Purkinje neurons transfected with FGF14b ${ }^{W T}$ or FGF14 ${ }^{N T}$. The number of neurons tested, $N$, is in parentheses. The current-voltage relationship for Scrambled control shRNA (from Figure 1) is shown for comparison. (C) Voltage dependence of $\mathrm{Na}_{V}$ channel activation and steady-state inactivation in cerebellar Purkinje neurons transfected with FGF14b $\mathrm{b}^{\mathrm{WT}}$ or FGF14 $\Delta^{\mathrm{NT}}$. The number of neurons tested, $N$, is in parentheses. The curves for Scrambled control shRNA (from Figure 1) are shown for comparison. (D) T of inactivation at the indicated test voltages. The number of neurons tested, $N$, is in parentheses. (E) Exemplar normalized TTX-sensitive late $\mathrm{Na}_{\mathrm{V}}$ currents at $-20 \mathrm{mV}$ (measured at $150 \mathrm{~ms}$, arrowhead) from a holding potential of $-90 \mathrm{mV}$. The number of neurons tested, $N$, is in parentheses. ${ }^{* *} p<0.01$. (F) Overlay of $N a v$ resurgent currents recorded from cerebellar Purkinje neurons transfected with FGF14 $\Delta^{N T}$ or FGF14b ${ }^{W T}$ and ratio of peak Nav resurgent current (at $+20 \mathrm{mV}$ ) to transient Nav current (at $-10 \mathrm{mV}$ ). The number of neurons tested, $N$, is in parentheses. The average for FGF14 shRNA knockdown (Figure 1) is shown for comparison. ${ }^{* *} p<0.01$.

DOI: 10.7554/eLife.04193.006

Nevertheless, the actions of $\mathrm{Na}_{\vee} \mathrm{\beta} 4$ are not sufficient to generate resurgent $\mathrm{Na}_{\vee}$ current (Chen et al., 2008; Aman et al., 2009), suggesting that other components of the $\mathrm{Na}_{V}$ channel complex may be necessary for proper regulation of resurgent $\mathrm{Na}_{v}$ current in cerebellar Purkinje neurons. Here, our knockdown experiments and expression of the dominant negative FGF14b $\Delta^{\mathrm{NT}}$ show that FGF14b, and 


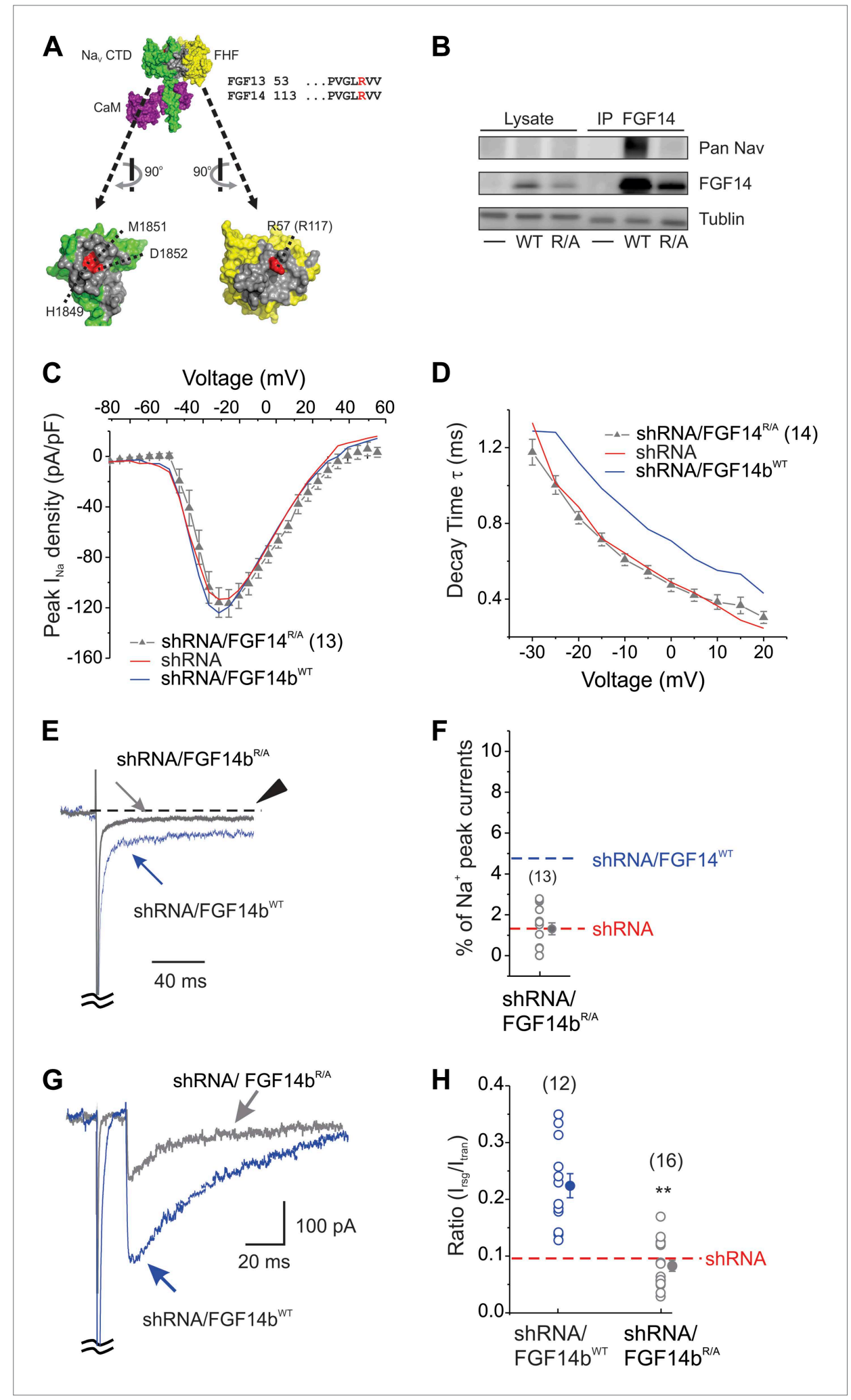

Figure 4. The FGF14b/A mutant that prevents interaction with the $\mathrm{Na}{ }_{\mathrm{V}} \mathrm{C}$-terminus cannot rescue $\mathrm{Na}_{\mathrm{v}}$ kinetic effects of FGF14 knockdown. (A) Surface representation of the crystal structure of a ternary complex containing the Nav1.5 C-terminus domain (CTD, green), FGF13 (yellow), and calmodulin (purple); the interaction surfaces are colored gray (PDB ID: 4DCK). The critical R57 in FGF13 (equivalent to R117 in FGF14) is indicated in red, as is its binding pocket Figure 4. Continued on next page 
Figure 4. Continued

on the Nav1.5 CTD. (B) Co-immunoprecipitation (IP) of Nav1.6 and FGF14bwT or FGF14b ${ }^{R / A}$ expressed in HEK293 cells, showing that the FGF14bR/A is unable to interact with the intact Nav1.6. Immunoblots (IB) were performed with the indicated antibodies. (C) Current-voltage relationship (normalized to cell capacitance) of transient $\mathrm{Nav}_{\mathrm{v}}$ currents from cerebellar Purkinje neurons transfected with FGF14b/A. The number of neurons tested, $N$, is in parentheses. The current-voltage relationship for FGF14 knockdown (shRNA) and knockdown rescued with shRNA-insensitive FGF14b ${ }^{W T}$ (shRNA/FGF14bWT) from Figure 1 are shown for comparison. (D) $\mathrm{T}$ of inactivation at the indicated test voltages. The number of neurons tested, $N$, is in parentheses. (E) Exemplar normalized TTX-sensitive late $\mathrm{Na}_{V}$ currents at $-20 \mathrm{mV}$ (measured at $150 \mathrm{~ms}$, arrowhead) from a holding potential of $-90 \mathrm{mV}$ and $(\mathbf{F})$ amplitude of late $\mathrm{Na}_{\mathrm{V}}$ current as a \% of peak (transient) $\mathrm{Na}_{\mathrm{V}}$ current. The number of neurons tested, $\mathrm{N}$, is in parentheses. Averages for shRNA and for shRNA/FGF14b"wT (see Figure 1) are shown for comparison. (G) Overlay of Nav resurgent currents recorded from cerebellar Purkinje neurons transfected with FGF14bR/A or FGF14b ${ }^{W T}$ and $(\mathbf{H})$ ratio of peak $\mathrm{Nav}_{\mathrm{V}}$ resurgent current (at $+20 \mathrm{mV}$ ) to transient $\mathrm{Na}_{\mathrm{v}}$ current (at $-10 \mathrm{mV}$ ). The number of neurons tested, $N$, is in parentheses. The average for FGF14 shRNA knockdown (Figure 1) is shown for comparison. ${ }^{\star \star} p<0.01$.

DOI: 10.7554/eLife.04193.007

specifically its $\mathrm{N}$-terminus, strongly influence resurgent $\mathrm{Na}_{\mathrm{v}}$ current. FGF14 knockdown caused a $\sim 60 \%$ reduction. Expression of FGF14 ${ }^{N T}$ was even more efficient, resulting in a $\sim 85 \%$ reduction, perhaps because overexpression of FGF14 ${ }^{\mathrm{NT}}$ was more efficient in replacing endogenous FGF14b than shRNA knockdown was in eliminating endogenous FGF14b. Thus, FGF14 may cooperate with $\mathrm{Na} \mathrm{B}_{\mathrm{\beta}} \mathrm{H}$ to generate resurgent current, perhaps by biasing $\mathrm{Na}_{\vee} 1.6$ channels towards inactivation and thereby disadvantaging the blocking particle. Our results examining effects on total $\mathrm{Nav}_{\mathrm{v}}$ current must be assessed in the context of FGF14 effects not only on $\mathrm{Na}_{v} 1.6$ channels but also on $\mathrm{Na}_{v} 1.1$ channel, the other major source of $\mathrm{Na}_{v}$ currents in cerebellar Purkinje neurons (Kalume et al., 2007). Those $\mathrm{Na}_{v}$ channels are also influence by FGF14 (Lou et al., 2005). Thus, the effects on resurgent current that we attribute to FGF14 may result from FGF14's overall influence of $\mathrm{Na}_{v}$ channel kinetics within Purkinje neurons.

Our results may also provide some insight into the more variable phenotypes and decreased penetrance in spinocerebellar ataxia patients with FGF14 haploinsufficiency (Dalski et al., 2005; Coebergh et alo, 2013) vs patients with a FGF14 mutation (FGF14bF150s) found in a large Dutch spinocerebellar ataxia kindred (van Swieten et al., 2003). Studies in hippocampal neurons suggest that the FGF14bF150s mutant exerts a dominant negative mechanism in which the axon initial segment is depleted of $\mathrm{Na}_{\mathrm{v}}$ channels and $\mathrm{Na}_{v}$ current density is reduced (Laezza et al., 2007). Here, we found no effect on $\mathrm{Na}_{v}$ current density in cerebellar Purkinje neurons after FGF14 knockdown. A reduction in $\mathrm{Na}_{\mathrm{v}}$ current density (with the FGF14bF150s mutation) compared to an effect solely on $\mathrm{Na}_{v}$ channel kinetics (with FGF14 haploinsufficiency) may explain the higher penetrance and decreased phenotypic variability in patients with the FGF14b ${ }^{\mathrm{F} 150 \mathrm{~S}}$ mutation.

An important aspect of this study examining effects on $\mathrm{Na}_{v}$ channel kinetics was that our analyses were performed in Purkinje neurons. Studying FHFs in their native cellular context appears to be crucial for defining their specific roles. Previous investigations of FGF14-dependent regulation of neuronal $\mathrm{Na}_{v}$ channels in heterologous expression systems led to different conclusions from experiments in neurons. For example, expression of $\mathrm{Na}_{v} 1.6$ and FGF14b ${ }^{\mathrm{WT}}$ in ND7/23 cells almost eliminated $\mathrm{Nav}$ current density (Laezza et al., 2009) while overexpression of FGF14bWT in hippocampal neurons increased $\mathrm{Na}_{\mathrm{v}}$ current density (Laezza et al., 2007). Similarly, expression of FGF14 $\Delta^{\mathrm{NT}}$ in ND7/23 cells increased current density, while here we observed that FGF14 $\Delta^{\mathrm{NT}}$ expression in cerebellar Purkinje neurons exerted dominant-negative effects upon $\mathrm{Na}_{v}$ channel kinetics, but no consequences for $\mathrm{Na}_{v}$ current density. While the etiology of the different results in neurons compared to heterologous expression systems is not known, we speculate that additional regulatory factors present in neurons are necessary for physiologic regulation of $\mathrm{Na}_{\mathrm{v}}$ channels by FHFs. Indeed, we have observed similarly disparate results for the related FGF13 and the cardiac Nav1.5 channel. In HEK293 cells, FGF13 co-expression reduces Nav1.5 current density (not shown), but we showed that the role FGF13 in cardiomyocytes is to increase Nav current density (Wang et al., 2011; Hennessey et al., 2013).

Finally, our data also provide information about possible consequences of FGF14 overexpression, hypothesized as pathologic in rare cases. Some patients with spinocerebellar ataxia, but not controls, harbor synonymous variants in FGF14. These variants encode a more frequently used codon than the 


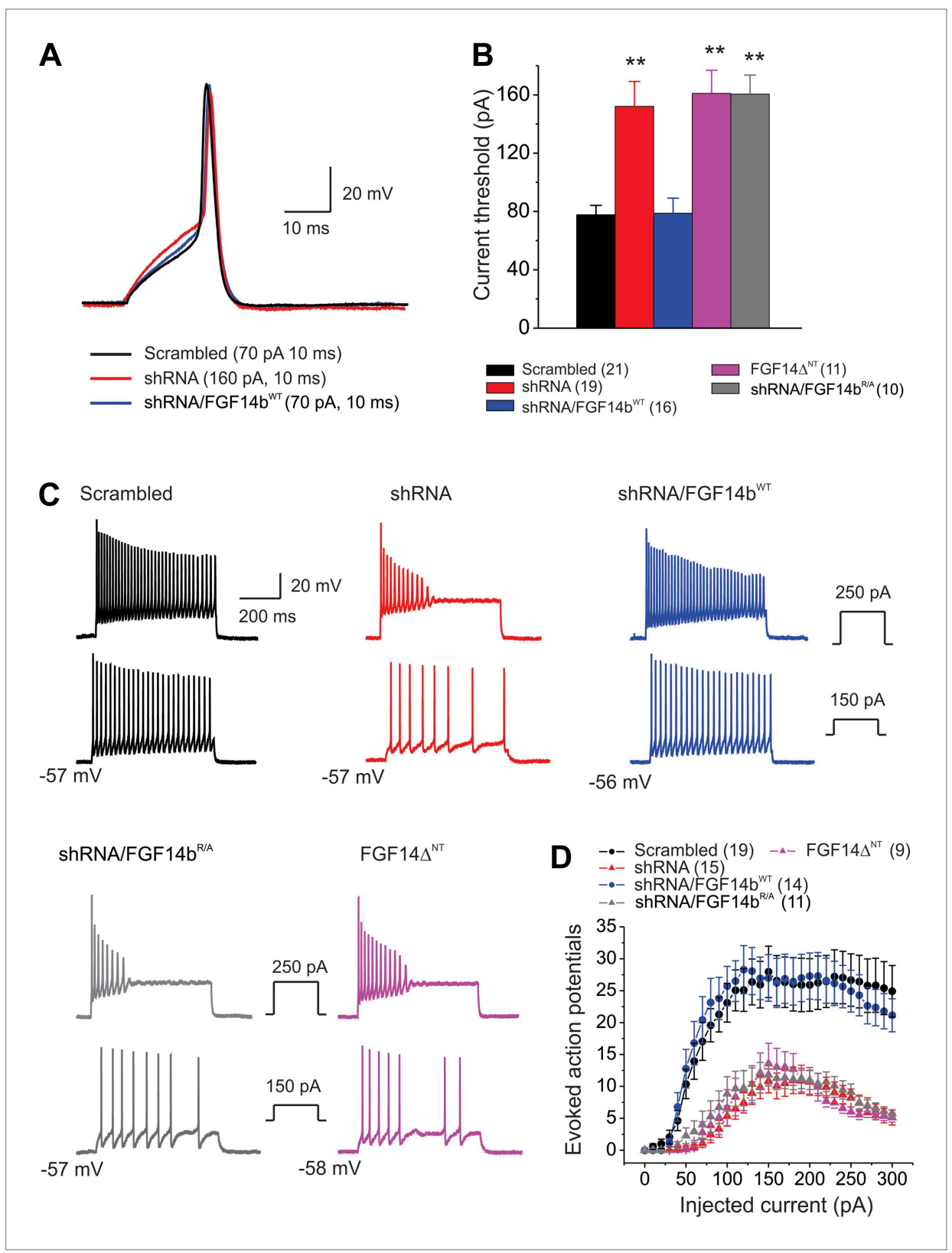

Figure 5. Action potential dynamics and repetitive spiking are dependent upon FGF14 and its N-terminus. (A) Overlay of single action potentials evoked with a 10 ms current injection (current amplitude shown in parentheses). (B) Current threshold to induce action potentials for the indicated conditions. ${ }^{*} p<0.01$. The number of neurons tested, $N$, is in parentheses. Additional summary data are presented in Table 2. (C) Example evoked action potentials for the indicated treatments at two separate current injection amplitudes (shown in insets). The resting membrane potential is indicated. (D) The number of evoked action potentials for the indicated amplitude of current injection. The number of neurons tested, $N$, is in parentheses.

DOI: 10.7554/eLife.04193.008

wild type sequence, leading to the hypothesis that patients with these variants would overexpress FGF14 as a cause of disease (Dalski et al., 2005). We found, however, that overexpression of FGF14b"WT did not affect current density or any of the measured $\mathrm{Na}_{v}$ kinetic properties (Figure 3 and Table 1). Thus, if these variants identified in spinocerebellar ataxia patients are truly associated with disease, our data suggest mechanisms other than FGF14 overexpression.

In summary, these data add to a growing appreciation of physiologic and pathophysiologic roles for FHFs in neurons. In the case of spinocerebellar ataxia, our data suggest that FGF14 is a critical 
Table 2. Intrinsic membrane properties and single action potential (AP) characteristics measured in cerebellar Purkinje neurons

\begin{tabular}{|c|c|c|c|c|c|}
\hline & Scrambled & shRNA & shRNA/FGF14bWT & shRNA/FGF14bRA & FGF14 $\Delta^{\mathrm{NT}}$ \\
\hline Input resistance (M $\Omega$ ) & $221.8 \pm 15.8(7)$ & $238.0 \pm 49.5(11)$ & $266.6 \pm 24.5(11)$ & $225.9 \pm 10.8(6)$ & $269.5 \pm 30.2(6)$ \\
\hline $\begin{array}{l}\text { Resting membrane } \\
\text { potential (mV) }\end{array}$ & $-54.5 \pm 1.3(21)$ & $-55.8 \pm 1.2(19)$ & $-54.4 \pm 1.0(16)$ & $-55.4 \pm 0.7(10)$ & $-54.9 \pm 1.4(11)$ \\
\hline Current threshold (pA) & $77.8 \pm 6.4(21)$ & $142.1 \pm 18.5(19)^{\star \star}$ & $78.8 \pm 10.4(16)$ & $170.5 \pm 16.7(10)^{\star \star}$ & $191.0 \pm 22.1(11)^{\star \star}$ \\
\hline AP threshold (mV) & $-35.6 \pm 1.0(21)$ & $-32.8 \pm 1.2(19)$ & $-34.5 \pm 0.8(16)$ & $-32.8 \pm 1.4(10)$ & $-32.7 \pm 0.8(11)$ \\
\hline AP amplitude (mV) & $78.8 \pm 3.2(21)$ & $77.5 \pm 2.8(19)$ & $78.9 \pm 4.5(16)$ & $79.1 \pm 4.3(10)$ & $73.1 \pm 4.7(11)$ \\
\hline AP duration (ms) & $2.3 \pm 0.2(21)$ & $2.0 \pm 0.1(19)$ & $2.2 \pm 0.1(16)$ & $1.8 \pm 0.1(10)$ & $2.1 \pm 0.3(11)$ \\
\hline
\end{tabular}

Mean \pm s.e.m. $(n),{ }^{* *} p<0.01$ compared to Scrambled control.

DOI: $10.7554 /$ eLife.04193.009

regulator of the ability of cerebellar Purkinje neuron $\mathrm{Na}_{v}$ channels to support resurgent $\mathrm{Na}_{v}$ current and thereby allow Purkinje neurons to fire repetitively. Thus, we provide a molecular understanding for the observation that FGF14 regulates Purkinje neuron intrinsic excitability (Shakkottai et al., 2009). In combination with our data showing that FGF14 also regulates presynaptic voltage-gated $\mathrm{Ca}^{2+}$ channels at the cerebellar granule cell to Purkinje cell synapse, these data pinpoint several specific mechanisms by which mutations in FGF14 underlie spinocerebellar ataxia.

\section{Materials and methods}

\section{Primary cerebellar neuron culture and transfection}

This study was performed in strict accordance with the recommendations in the Guide for the Care and Use of Laboratory Animals of the National Institutes of Health. All of the animals were handled according to approved Institutional Animal Care and Use Committee (IACUC) of Duke University (protocol \#A292-13-11). Primary dissociated cerebellar neurons were cultured as previously described (Yan et al., 2013) with some modifications. Briefly, primary cultures were prepared from P6-P8 C57BL6 mice. Cerebella were excised, dissected on ice, digested with $0.25 \%$ trypsin for 10 min at $37^{\circ} \mathrm{C}$ with Dulbecco's Modified Eagle's Medium (DMEM, Sigma, St. Louis, MO), and dissociated into single cells by gentle trituration. The cells were seeded onto coverslips coated with $50 \mu \mathrm{g} / \mathrm{ml}$ poly-D-lysine (Sigma) and $25 \mu \mathrm{g} / \mathrm{ml}$ laminin (Sigma) at a density of $2.5-3.0 \times 10^{5}$ cells/coverslip in DMEM supplemented with $10 \%$ heat-inactivated fetal bovine serum (FBS). The neurons were maintained in a humidified incubator in $5 \% \mathrm{CO}_{2}$ at $37^{\circ} \mathrm{C}$. After $15-16 \mathrm{hr}$, the medium was replaced with Basal Medium Eagle (BME, Sigma) supplemented with 2\% B27 (Invitrogen), 5\% FBS, $25 \mu$ M uridine, $70 \mu \mathrm{M}$ 5-fluorodeoxyuridine, and $20 \mathrm{mM} \mathrm{KCl}$. Neurons were transiently transfected at 4 days in vitro with $1 \mu \mathrm{g}$ plasmid DNA and/or shRNA plasmids per coverslip with calcium phosphate. Experiments were performed 8-10 days after transfection (12-14 days in vitro). To achieve good voltage control, all recordings were performed in neurons cultured no longer than 14 days in vitro.

\section{shRNA and cDNA construction}

shRNAs targeted to FGF14 were designed with Invitrogen's RNAi Designer as previously described (Yan et al., 2013) and the sequences were cloned into pLVTHM (Addgene). After evaluating several candidates, we found that the most effective shRNA sequence was 5' CGCGTGGA GGCAAACCAGTCAACAAGTGCATTCAAGAGATGCACTTGTTGACTGGTTTGC CTCCTTTTTTAT 3', which was used for the experiments described here. The scrambled shRNA which bears no homology to genes in the rodent genome (Wang et al., 2011) has the sequence: 5'-CGCGTGACCC TTAGTTTATACCTATTCAAGAGATAGGTATAAACTAAGGGTCTTTTTTAT-3'. FGF14 rescue and overexpression experiments were performed with FGF14 constructs (either full-length or with the N-terminus truncated) cloned into pcDNA3.1 also containing tdTomato. Mutagenesis to obtain FGF14b/A was performed using QuikChange (Agilent). All plasmids were verified by sequencing.

\section{Electrophysiological recordings}

Purkinje neurons were identified by their characteristic teardrop morphology and large size. Wholecell $\mathrm{Na}_{v}$ currents and membrane voltage were recorded at $23-25^{\circ} \mathrm{C}$ using an EPC 10 USB patch 
amplifier (HEKA Elektronik). The signal was filtered at $2.9 \mathrm{~Hz}$ and digitized at $20 \mathrm{~Hz}$. $\mathrm{Na}_{\mathrm{v}}$ currents were recorded with an extracellular solution containing (in $\mathrm{mM}$ ) $124 \mathrm{NaCl}, 20 \mathrm{TEA}-\mathrm{Cl}$ (tetraethylammonium Chloride), 5 HEPES (4-(2-hydroxyethyl)-1-piperazineethanesulfonic acid), 10 glucose, $0.3 \mathrm{CdCl}_{2}, 2 \mathrm{BaCl}_{2}$, and 4-AP (4-aminopyridine). $\mathrm{NaOH}$ was added to achieve pH 7.3 (300-310 mOsm). Borosilicate glass patch pipettes (resistances within 3-4 $\mathrm{M} \Omega$ ) were filled with the following internal solution (in mM): $125 \mathrm{CsF}, 10 \mathrm{NaCl}, 10 \mathrm{HEPES}, 15 \mathrm{TEA}-\mathrm{Cl}, 1.1$ ethylene glycol tetraacetic acid (EGTA), and $0.5 \mathrm{Na}$-guanosine-5'-triphosphate ( $\mathrm{Na}-\mathrm{GTP}), \mathrm{pH}$ adjusted to 7.3 with $\mathrm{CsOH}(290-300 \mathrm{mOsm}$ ). Tetrodotoxin (TTX)-sensitive $\mathrm{Na}_{v}$ currents were isolated by subtraction of recordings performed in $1 \mu \mathrm{M}$ TTX from the control recordings. Series resistance was compensated $>70 \%$. Current-clamp recordings were performed after obtaining seal resistances $>1.2 \mathrm{G} \Omega$. The internal solution was (in $\mathrm{mM}$ ) $130 \mathrm{~K}$-gluconate, $5 \mathrm{NaCl}, 2 \mathrm{MgCl}_{2}, 10$ HEPES, $4 \mathrm{Mg}$-ATP, $0.5 \mathrm{Na}-\mathrm{GTP}, 0.2$ EGTA, and 10 phosphocreatine. $\mathrm{KOH}$ was used to obtain $\mathrm{pH} 7.3$ (290-300 mOsm). The external solution was (in mM) $140 \mathrm{NaCl}, 5 \mathrm{KCl}, 2 \mathrm{CaCl}_{2}, 1 \mathrm{MgCl}_{2}, 5 \mathrm{HEPES}$, and 10 glucose, pH adjusted to 7.3 with $\mathrm{NaOH}$. Resting membrane potential was directly measured in current-clamp mode after membrane rupture and only cells with a resting membrane potential more negative than $-50 \mathrm{mV}$ were studied. The liquid junction potential was not corrected. Input resistance was determined from membrane voltage deflection, evoked by 600 -ms hyperpolarizing current injections ( 0 to -300 pA in steps of $50 \mathrm{pA}$ ) and calculated from the measured slope. Single action potentials were elicited by 10 ms depolarizing current injections with 5-pA increments. All drugs were from Sigma Aldrich, except for TTX (Abcam Biochemicals).

\section{Protocols and data analysis}

Data analysis was performed using FitMaster (HEKA), Excel (Microsoft), and Origin software. All averaged data are presented as mean \pm SEM. Statistical significance was determined using Student's $t$ or one-way ANOVA tests. Calculated $p$ values of $\leq 0.05$ were accepted as evidence of statistically significant differences. For current amplitude, neurons were held at $-90 \mathrm{mV}$ and transient $\mathrm{Na}_{\mathrm{v}}$ current was elicited by depolarizing pulses of $20 \mathrm{~ms}$ from $-90 \mathrm{mV}$ to $+55 \mathrm{mV}$ in $5-\mathrm{mV}$ increments. Current density was obtained by normalizing peak $\mathrm{Na}_{\vee}$ current to membrane capacitance. Resurgent $\mathrm{Na}_{\mathrm{V}}$ current was evoked with repolarizing steps from $+20 \mathrm{mV}$ to a range of voltages between $-80 \mathrm{mV}$ and $+5 \mathrm{mV}$ in $5-\mathrm{mV}$ increments for a 200-ms test pulse after $15 \mathrm{~ms}$ conditioning steps. $\mathrm{Na}_{\mathrm{v}}$ activation curves were obtained by transforming current data to conductance $(G)$, with the equation $G=I_{\mathrm{Na}} /\left(E_{m}-E_{\text {rev }}\right)$, where: $I_{\mathrm{Na}}$ is the peak current; $E_{m}$ is the membrane potential; and $E_{\text {rev }}$ is the reversal potential of $I_{N a}$; and fitted with a Boltzmann equation of the form: $\mathrm{G}=\mathrm{G}_{\max } /\left[1+\exp \left(V_{1 / 2}-V\right) / k\right]$, where $\mathrm{G}_{\max }$ is the extrapolated maximum $\mathrm{Na}^{+}$conductance, $\mathrm{V}$ is the test voltage, $\mathrm{V}_{1 / 2}$ is the half-activation voltage, and $\mathrm{k}$ is the slope factor. For $\mathrm{Na}_{\mathrm{V}}$ steady-state inactivation, a voltage step to $-20 \mathrm{mV}$ for $20 \mathrm{~ms}$ was applied from a holding potential of $-90 \mathrm{mV}$ to preferentially activate $I_{\mathrm{Na}}$ after pre-pulse conditioning voltage steps of $300 \mathrm{~ms}$ in duration (ranging from -90 to $+20 \mathrm{mV}$ ) in $5-\mathrm{mV}$ increments. Steady-state inactivation curves were constructed by plotting the normalized peak current amplitude elicited during the test pulse as a function of the conditioning pre-pulse. A Boltzmann relationship, $I / I_{\max }=\left(1+\exp \left(\left(V-V_{1 / 2}\right) / k\right)\right)^{-1}$ was used to fit the data where $I_{\max }$ is current elicited by the test pulse after a $-90-\mathrm{mV}$ prepulse; $V_{1 / 2}$ is half-inactivation voltage; $k$ is the slope. Late $\mathrm{Na}_{v}$ current was measured at $150 \mathrm{~ms}$ during a $200 \mathrm{~ms}$ depolarizing pulse to $-20 \mathrm{mV}$. The rate of decay of the transient $\mathrm{Na}_{V}$ current $(\mathrm{T}$ ) was obtained from a single exponential function, $I_{(t)}=I_{N a} \exp ^{(-t / \tau)}+I_{S S}$, where $I_{(t)}$ is the amplitude of the current at time $t ; I_{S S}$ is the steady-state current during a single voltage step.

In current clamp, action potential amplitude was measured as the peak voltage with respect to the baseline $10 \mathrm{~ms}$ before the peak of the action potential. The action potential duration was evaluated at half-amplitude. Evoked action potentials were elicited by injecting a depolarizing current from 0 pA to 300 pA for 600 ms duration with 10-pA increments.

\section{Immunoprecipitation and Western blotting}

Cerebella were isolated from two 5-week-old C57BL/6J mice and homogenized with a mortar and pestle in $8 \mathrm{ml}$ of lysis buffer composed of $150 \mathrm{mM} \mathrm{NaCl}, 50 \mathrm{mM}$ Tris-Cl, $1 \%$ Triton, and $1 \%$ sodium deoxycholate. Lysate was incubated on ice for $2 \mathrm{hr}$, passed through a $20 \mathrm{~g}$ needle 20 times, and rocked end over end for $30 \mathrm{~min}$ at $4^{\circ} \mathrm{C}$. The lysate was cleared of insoluble material by centrifugation at $4000 \mathrm{rcf}$ at $4^{\circ} \mathrm{C}$ for $30 \mathrm{~min}$ followed by a second centrifugation at $17,100 \mathrm{rcf}$ at $4^{\circ} \mathrm{C}$ 
for $10 \mathrm{~min}$. The lysate was preincubated with $30 \mu \mathrm{l}$ of Protein A/G (Santa Cruz Biotechnology) beads for $2 \mathrm{hr}$ at $4^{\circ} \mathrm{C}$. The beads were gently spun down at $0.4 \mathrm{rcf}$ for $1 \mathrm{~min}$ to separate them from the lysate, which was then incubated with $20 \mu \mathrm{g}$ of either anti-FGF14 (NeuroMab) or non-immune mouse IgG (Santa Cruz Biotechnology) overnight at $4^{\circ} \mathrm{C}$. In order to immunoprecipitate protein complexes, $30 \mu \mathrm{l}$ of Protein A/G beads were added and incubated with the lysate for $2 \mathrm{hr}$. Beads were then washed three times with lysis buffer followed by elution in $2 \times$ LDS Sample Buffer (Novex NuPage) plus $10 \mathrm{mM}$ dithiothreiotol. Protein samples were run on 8-16\% Tris-glycine SDS page gels and transferred to PVDF membranes. Primary antibodies used were rabbit polyclonal anti $\mathrm{Na}_{v} 1.6$ from Millipore (1:200), anti- $\beta$-tubulin from Sigma (1:1000) as a loading control, and rabbit polyclonal anti-FGF14 (1:200), which was a kind gift from the Ornitz lab (Washington University, St. Louis). HEK293T cells on 100-mm plates were transfected with Lipofectamine 2000 (Invitrogen) when cells were at $\sim 60 \%$ confluency with $9 \mu \mathrm{g}$ of $\mathrm{Nav} 1.6$ and $3 \mu \mathrm{g}$ of FGF14b ${ }^{\text {WT }}$ or FGF14b ${ }^{\text {R/A }}$. Cells were washed with ice-cold PBS $60 \mathrm{hr}$ after transfection, and cell lysates were prepared with the addition of lysis buffer containing $150 \mathrm{~mm} \mathrm{NaCl}, 50 \mathrm{~mm}$ Tris- $\mathrm{HCl}, \mathrm{pH} \mathrm{7.5,1 \%}$ Triton with protease inhibitor (Roche). The pelleted cells were pipetted up and down 20 times with lysis buffer, incubated at $4^{\circ} \mathrm{C}$ for $1 \mathrm{hr}$ and then centrifuged at $16,000 \times \mathrm{g}$ for $10 \mathrm{~min}$ at $4^{\circ} \mathrm{C}$. Immunoprecipitation was performed on $2 \mathrm{mg}$ of lysate with $2 \mu \mathrm{g}$ of anti-FGF14 antibody (Neuromab). The samples were rocked gently at $4^{\circ} \mathrm{C}$ for $1 \mathrm{hr}$ followed by addition of $30 \mu \mathrm{l}$ of protein A/G-agarose slurry. The samples were rotated overnight at $4^{\circ} \mathrm{C}$ and microcentrifuged at $7000 \mathrm{rpm}$ for $2 \mathrm{~min}$. After washing with lysis buffer three times, $40 \mu \mathrm{l}$ of loading buffer was added to the pellet, and protein was eluted from the beads by heating at $70^{\circ} \mathrm{C}$ for $20 \mathrm{~min}$. The samples were subjected to NuPAGE 8-16\% Bis-Tris gels (Invitrogen). The proteins were transferred to nitrocellulose membranes and subsequently immunoblotted with the anti-FGF14, anti-pan $\mathrm{Na}_{v}$ antibody, and anti-tubulin antibody.

\section{Acknowledgements}

We thank Dr Amanda H Lewis for insightful discussions. This work was supported by NIH R01 HL071165 and R01 HL112918 (GSP).

\section{Additional information}

Funding

\begin{tabular}{lll} 
Funder & Grant reference number & Author \\
\hline $\begin{array}{l}\text { National Heart, Lung, and Blood } \\
\text { Institute }\end{array}$ & R01 HL071165 & Geoffrey S Pitt \\
\hline $\begin{array}{l}\text { National Heart, Lung, and Blood } \\
\text { Institute }\end{array}$ & R01 HL112918 & Geoffrey S Pitt \\
\hline
\end{tabular}

The funder had no role in study design, data collection and interpretation, or the decision to submit the work for publication.

Author contributions

HY, Conception and design, Acquisition of data, Analysis and interpretation of data, Drafting or revising the article; JLP, CW, Acquisition of data, Analysis and interpretation of data, Drafting or revising the article; GSP, Conception and design, Analysis and interpretation of data, Drafting or revising the article

Author ORCIDs

Geoffrey S Pitt, (iD http://orcid.org/0000-0003-2246-0289

Ethics

Animal experimentation: This study was performed in strict accordance with the recommendations in the Guide for the Care and Use of Laboratory Animals of the National Institutes of Health. All of the animals were handled according to approved institutional animal care and use committee (IACUC) of Duke University for the protocol \#A292-13-11. 


\section{Additional files}

Major dataset

The following previously published dataset was used:

\begin{tabular}{lllll} 
Author(s) & Year & Dataset title & Dataset ID and/or URL & $\begin{array}{l}\text { and accessibility } \\
\text { information }\end{array}$ \\
\hline Wang C, Chung BC, & 2012 & $\begin{array}{l}\text { Crystal structure of the C-terminus } \\
\text { of voltage-gated sodium channel } \\
\text { in complex with FGF13 and CaM }\end{array}$ & $\begin{array}{l}\text { http://www.pdb.org/ } \\
\text { pdb/explore/explore. } \\
\text { do?structureld=4DCK }\end{array}$ & $\begin{array}{l}\text { Publicly available at } \\
\text { RCSB Protein Data } \\
\text { Bank. }\end{array}$
\end{tabular}

\section{References}

Aman TK, Grieco-Calub TM, Chen C, Rusconi R, Slat EA, Isom LL, Raman IM. 2009. Regulation of persistent Na current by interactions between beta subunits of voltage-gated $\mathrm{Na}$ channels. The Journal of Neuroscience 29:2027-2042. doi: 10.1523/JNEUROSCI.4531-08.2009.

Chen Y, Yu FH, Sharp EM, Beacham D, Scheuer T, Catterall WA. 2008. Functional properties and differential neuromodulation of $\mathrm{Na}(\mathrm{v}) 1.6$ channels. Molecular and Cellular Neurosciences 38:607-615. doi: 10.1016/j. mcn.2008.05.009.

Coebergh JA, Fransen van de Putte DE, Snoeck IN, Ruivenkamp C, van Haeringen A, Smit LM. 2013. A new variable phenotype in spinocerebellar ataxia 27 (SCA 27) caused by a deletion in the FGF14 gene. European Journal of Paediatric Neurology 18:413-415. doi: 10.1016/j.ejpn.2013.10.006.

Dalski A, Atici J, Kreuz FR, Hellenbroich Y, Schwinger E, Zühlke C. 2005. Mutation analysis in the fibroblast growth factor 14 gene: frameshift mutation and polymorphisms in patients with inherited ataxias. European Journal of Human Genetics 13:118-120. doi: 10.1038/sj.ejhg.5201286.

Dover K, Solinas S, D'Angelo E, Goldfarb M. 2010. Long-term inactivation particle for voltage-gated sodium channels. The Journal of Physiology 588:3695-3711. doi: 10.1113/jphysiol.2010.192559.

Goldfarb M, Schoorlemmer J, Williams A, Diwakar S, Wang Q, Huang X, Giza J, Tchetchik D, Kelley K, Vega A, Matthews G, Rossi P, Ornitz DM, D'Angelo E. 2007. Fibroblast growth factor homologous factors control neuronal excitability through modulation of voltage-gated sodium channels. Neuron 55:449-463. doi: 10.1016/j.neuron.2007.07.006.

Grieco TM, Malhotra JD, Chen C, Isom LL, Raman IM. 2005. Open-channel block by the cytoplasmic tail of sodium channel beta4 as a mechanism for resurgent sodium current. Neuron 45:233-244. doi: 10.1016/j. neuron.2004.12.035.

Gruol DL, Franklin CL. 1987. Morphological and physiological differentiation of Purkinje neurons in cultures of rat cerebellum. The Journal of Neuroscience 7:1271-1293.

Hennessey JA, Marcou CA, Wang C, Wei EQ, Wang C, Tester DJ, Torchio M, Dagradi F, Crotti L, Schwartz PJ, Ackerman MJ, Pitt GS. 2013. FGF12 is a candidate Brugada syndrome locus. Heart Rhythm 10:1886-1894. doi: 10.1016/j.hrthm.2013.09.064.

Hennessey JA, Wei EQ, Pitt GS. 2013. Fibroblast growth factor homologous factors modulate cardiac calcium channels. Circulation Research 113:381-388. doi: 10.1161/CIRCRESAHA.113.301215.

Kalume F, Yu FH, Westenbroek RE, Scheuer T, Catterall WA. 2007. Reduced sodium current in Purkinje neurons from Nav1.1 mutant mice: implications for ataxia in severe myoclonic epilepsy in infancy. The Journal of Neuroscience 27:11065-11074. doi: 10.1523/JNEUROSCI.2162-07.2007.

Khaliq ZM, Gouwens NW, Raman IM. 2003. The contribution of resurgent sodium current to high-frequency firing in Purkinje neurons: an experimental and modeling study. The Journal of Neuroscience 23:4899-4912.

Laezza F, Gerber BR, Lou JY, Kozel MA, Hartman H, Craig AM, Ornitz DM, Nerbonne JM. 2007. The FGF14(F145S) mutation disrupts the interaction of FGF14 with voltage-gated $\mathrm{Na}+$ channels and impairs neuronal excitability. The Journal of Neuroscience 27:12033-12044. doi: 10.1523/JNEUROSCI.2282-07.2007.

Laezza F, Lampert A, Kozel MA, Gerber BR, Rush AM, Nerbonne JM, Waxman SG, Dib-Hajj SD, Ornitz DM. 2009. FGF14 N-terminal splice variants differentially modulate Nav1.2 and Nav1.6-encoded sodium channels. Molecular and Cellular Neurosciences 42:90-101. doi: 10.1016/j.mcn.2009.05.007.

Liu C, Dib-Hajj SD, Waxman SG. 2001. Fibroblast growth factor homologous factor 1B binds to the $C$ terminus of the tetrodotoxin-resistant sodium channel rNav1.9a (NaN). The Journal of Biological Chemistry 276:18925-18933. doi: 10.1074/jbc.M101606200.

Lou JY, Laezza F, Gerber BR, Xiao M, Yamada KA, Hartmann H, Craig AM, Nerbonne JM, Ornitz DM. 2005. Fibroblast growth factor 14 is an intracellular modulator of voltage-gated sodium channels. The Journal of Physiology 569:179-193. doi: 10.1113/jphysiol.2005.097220.

Munoz-Sanjuan I, Smallwood PM, Nathans J. 2000. Isoform diversity among fibroblast growth factor homologous factors is generated by alternative promoter usage and differential splicing. The Journal of Biological Chemistry 275:2589-2597. doi: 10.1074/jbc.275.4.2589.

Raman IM, Bean BP. 1999. Ionic currents underlying spontaneous action potentials in isolated cerebellar Purkinje neurons. The Journal of Neuroscience 19:1663-1674.

Raman IM, Bean BP. 1997. Resurgent sodium current and action potential formation in dissociated cerebellar Purkinje neurons. The Journal of Neuroscience 17:4517-4526. 
Raman IM, Sprunger LK, Meisler MH, Bean BP. 1997. Altered subthreshold sodium currents and disrupted firing patterns in Purkinje neurons of Scn8a mutant mice. Neuron 19:881-891. doi: 10.1016/S0896-6273(00)80969-1. Rush AM, Wittmack EK, Tyrrell L, Black JA, Dib-Hajj SD, Waxman SG. 2006. Differential modulation of sodium channel $\mathrm{Na}(\mathrm{v}) 1.6$ by two members of the fibroblast growth factor homologous factor 2 subfamily. The European Journal of Neuroscience 23:2551-2562. doi: 10.1111/j.1460-9568.2006.04789.x.

Shakkottai VG, Xiao M, Xu L, Wong M, Nerbonne JM, Ornitz DM, Yamada KA. 2009. FGF14 regulates the intrinsic excitability of cerebellar Purkinje neurons. Neurobiology of Disease 33:81-88. doi: 10.1016/j.nbd.2008.09.019.

Smallwood PM, Munoz-Sanjuan I, Tong P, Macke JP, Hendry SH, Gilbert DJ, Copeland NG, Jenkins NA, Nathans J. 1996. Fibroblast growth factor (FGF) homologous factors: new members of the FGF family implicated in nervous system development. Proceedings of the National Academy of Sciences of USA 93:9850-9857. doi: 10.1073/pnas.93.18.9850.

van Swieten JC, Brusse E, de Graaf BM, Krieger E, van de Graaf R, de Koning I, Maat-Kievit A, Leegwater P, Dooijes D, Oostra BA, Heutink P. 2003. A mutation in the fibroblast growth factor 14 gene is associated with Autosomal dominant Cerebral ataxia. The American Journal of Human Genetics 72:191-199. doi: 10.1086/345488.

Wang C, Chung BC, Yan H, Lee SY, Pitt GS. 2012. Crystal structure of the ternary complex of a NaV C-terminal domain, a fibroblast growth factor homologous factor, and calmodulin. Structure 20:1167-1176. doi: 10.1016/ j.str.2012.05.001.

Wang C, Hennessey JA, Kirkton RD, Wang C, Graham V, Puranam RS, Rosenberg PB, Bursac N, Pitt GS. 2011. Fibroblast growth factor homologous factor 13 regulates $\mathrm{Na}+$ channels and conduction velocity in murine hearts. Circulation Research 109:775-782. doi: 10.1161/CIRCRESAHA.111.247957.

Wang Q, Bardgett ME, Wong M, Wozniak DF, Lou J, McNeil BD, Chen C, Nardi A, Reid DC, Yamada K, Ornitz DM. 2002. Ataxia and paroxysmal dyskinesia in mice lacking axonally transported FGF14. Neuron 35:25-38. doi: 10.1016/S0896-6273(02)00744-4.

Wang Q, McEwen DG, Ornitz DM. 2000. Subcellular and developmental expression of alternatively spliced forms of fibroblast growth factor 14. Mechanisms of Development 90:283-287. doi: 10.1016/S0925-4773(99)00241-5. Yan H, Pablo JL, Pitt GS. 2013. FGF14 regulates presynaptic Ca2+ channels and synaptic transmission. Cell Reports 4:66-75. doi: 10.1016/j.celrep.2013.06.012. 